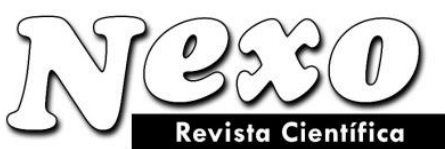

Vol. 36, No. 06, pp. 1677-1688/Diciembre 2021

\title{
The elimination of the consequences of transport emergencies
}

\section{La eliminación de las consecuencias de las emergencias de transporte}

\author{
Valeriy Borisovich Vilkov ${ }^{1, *}$, Andrey Klimentevich Chernykh ${ }^{2}$, Igor Gennadevich Malygin ${ }^{2,3}$, \\ Yuriy Dmitrievich Motorygin ${ }^{2}$, Alexandr Vladimirovich Skripka ${ }^{2}$ \\ ${ }^{1}$ Military Academy of Material Support of General A.V. Hrulyov, St. Petersburg, Russia \\ ${ }^{2}$ Saint-Petersburg University of State Fire Service of EMERCOM of Russia, St. Petersburg, Russia \\ ${ }^{3}$ Solomenko Institute of Transport Problems of the Russian Academy of Sciences, St. Petersburg, Russia \\ *email: v_b_vilkov@mail.ru
}

(recibido/received: 12-octubre-2021; aceptado/accepted: 01-diciembre-2021)

\begin{abstract}
The problem of multicriteria optimization in relation to the decisions made about organizing the material and technical support for equipment and personnel of the Ministry of the Russian Federation for Civil Defence, Emergencies and Elimination of Consequences of Natural Disasters (EMERCOM of Russia) in the context of emergency response on transport has been explored in this article. The existing approaches have been indicated, and another approach to building a single generalized criterion by the given partial criteria for the multicriteria optimization problem has been proposed. The verbal statement of the considered problem of multicriteria optimization has been provided. The goal of the study is to develop a method for solving this multicriteria optimization problem using fuzzy sets, fuzzy logic, and the Mamdani's fuzzy inference algorithm. A substantial example has been provided, illustrating the application of the stated theoretical provisions for solving the problem of choosing the best option for the equipment and personnel of the EMERCOM of Russia to liquidate the consequences of emergency situations on transport. In terms of novelty, it must be noted that the indicator (output variable) and parameters (input variables) of the problem have been defined ambiguously, fuzzily, which allows to use the efficient mathematical tools of the theory of fuzzy sets, fuzzy logic, and the Mamdani's fuzzy inference algorithm to solve this problem.
\end{abstract}

Keywords: Material and technical support; Material and technical equipment; Organization.

\section{RESUMEN}

El problema de la optimización multicriterio en relación con las decisiones tomadas sobre la organización del soporte material y técnico para equipos y personal del Ministerio de la Federación Rusa de Defensa Civil, Emergencias y Eliminación de Consecuencias de Desastres Naturales (EMERCOM de Rusia) en el contexto de este artículo se ha explorado la respuesta de emergencia en el transporte. Se han indicado los enfoques existentes y se ha propuesto otro enfoque para construir un único criterio generalizado mediante los criterios parciales dados para el problema de optimización multicriterio. Se ha proporcionado la declaración verbal del problema considerado de optimización multicriterio. El objetivo del estudio es desarrollar un método para resolver este problema de optimización multicriterio utilizando conjuntos difusos, lógica difusa y el algoritmo de inferencia difusa de Mamdani. Se ha proporcionado un ejemplo sustancial, que ilustra la aplicación de las disposiciones teóricas establecidas para resolver el problema de 
elegir la mejor opción para el equipo y el personal del EMERCOM de Rusia para liquidar las consecuencias de las situaciones de emergencia en el transporte. En cuanto a la novedad, cabe destacar que el indicador (variable de salida) y los parámetros (variables de entrada) del problema se han definido de forma ambigua, difusa, lo que permite utilizar las eficientes herramientas matemáticas de la teoría de conjuntos difusos, lógica difusa, y el algoritmo de inferencia difusa de Mamdani para resolver este problema.

Palabras claves: Soporte material y técnico; Material y equipo técnico; Organización.

\section{INTRODUCCIÓN}

The problem of optimizing the organization of material and technical support for EMERCOM groups often needs to be solved when developing a decision on the use of equipment and personnel of the EMERCOM of Russia in the context of eliminating the consequences of emergency situations on transport. The authors believe that it is relevant to consider the optimal solution to the problem of organizing the material and technical support for equipment and personnel of the EMERCOM of Russia in the context of emergency response on transport in the article. There is a high probability of the spread of fires along the road routes, destruction of bridges, tunnels, and other objects of transport infrastructure, as well as the unlawful actions of attackers (terrorists) under these conditions. Therefore, the delivery of material and technical equipment and personnel of the EMERCOM of Russia is difficult and often impossible on some routes. As such, the verbal statement of this problem is formed as follows: to determine the plan for the delivery of material and technical equipment from warehouses and bases to the equipment and personnel of the EMERCOM of Russia, maximizing the reliability of the delivery of these materials and at the same time minimizing transportation costs (Chernykh y Kopkin y Skoptsov, 2015; Chernykh y Kozlova, y Vilkov, 2015).

The following two criteria are considered in the problem to be solved: the reliability of the plan for the delivery of material and technical means, which plays the role of an operational criterion, and transportation costs for the delivery of material means - an economic criterion, with the first criterion being of the highest priority.

The main content of the article is related to the use of the theory of fuzzy sets and fuzzy logic to solve the problem formulated above. Its founder is L. Zadeh (1976; 1965), and its main provisions are described, for example, in (Yakhyaeva, 2006; Leonenkov, 2005; Anisimov, Anisimov y Botvin, 2006; Shtovba, 2001; 2007; Kosko, 1994; Vilkov y Kozlova 2015; Borisov y Krumberg y Fedorov, 1990; Averkin, et al. 1986)

\section{BASIC CONCEPTS}

Let there be a set $X$, which is called universal. A fuzzy set $\hat{A}$ on the universal set $X$ (hereinafter just a fuzzy set) is a pair $\left(A, \mu_{\widehat{A}}(x)\right)$, where $A \subseteq X, \mu_{\widehat{A}}(x)$ is the function defined on the universal set $X$ and taking values from zero to one. This function is called the membership function of the fuzzy set $\hat{A}$, its value for the given $x$ describes the degree of confidence that $x$ is an element of the fuzzy set $\hat{A}$. The values of the membership function will later be often called the degree of certainty or reliability.

Below are some of the necessary operations: the intersection and union of fuzzy sets (Vilkov y Kozlova, 2015). A fuzzy set, which is the intersection of fuzzy sets $\hat{A}$ and $\hat{B}$, is denoted as $\hat{A} \cap \hat{B}$, and its membership function $\mu_{\hat{A} \cap \hat{B}}(x)$ is found according to the following rule:

$$
\mu_{\widehat{A} \cap \hat{B}}(x)=\min \left\{\mu_{\widehat{A}}(x), \mu_{\widehat{B}}(x)\right\} .
$$


A fuzzy set, which is the union of fuzzy sets $\hat{A}$ and $\hat{B}$ is denoted as $\hat{A} \cup \hat{B}$, and its membership function $\mu_{\hat{A} \cup \hat{B}}(x)$ is found according to the following rule:

$$
\mu_{\hat{A} \cup \hat{B}}(x)=\max \left\{\mu_{\hat{A}}(x), \mu_{\widehat{B}}(x)\right\}
$$

Let us lay out the concepts required for further reasoning.

Let us denote the fuzzy variable statements that depend on a certain variable $u$ as $\tilde{A}(u)$ and $\tilde{B}(u)$, and the membership functions that specify the truth values of these variable statements as $\mu_{\tilde{A}}(u)$ and $\mu_{\tilde{B}}(u)$.

Fuzzy logical operations AND and OR ( $\wedge$ and $\vee$ ), conjunction and disjunction, similar to the set-theoretic operations of fuzzy intersection and fuzzy union, are performed according to the following rules:

$$
\begin{gathered}
\mu_{\overparen{A \wedge B}}(u)=\min \left\{\mu_{\widetilde{A}}(u), \mu_{\widetilde{B}}(u)\right\}, \\
\mu_{\widetilde{A V B}}(u)=\max \left\{\mu_{\widetilde{A}}(u), \mu_{\widetilde{B}}(u)\right\}
\end{gathered}
$$

\section{DESCRIPTION OF THE OPTIMIZATION TASK}

In the context of eliminating the consequences of emergency situations on transport, an optimal decision on the material and technical support for equipment and personnel of the EMERCOM of Russia should be developed and taken in the area of emergency response on transport, based on the solution of the transport linear programming problem. At the same time, it is assumed that the source data for making such a decision have not been obtained in full, and thus, when developing the solution, it becomes necessary to use fuzzy sets, fuzzy logic, and Mamdani's fuzzy inference algorithm (Chernykh y Kopkin y Skoptsov, 2015; Chernykh y Kozlova, y Vilkov, 2015; Vilkov y Kozlova, 2015). This may be, for example, due to the fact that for some reason not reviewed in this article, the material and technical support for equipment and personnel of the EMERCOM of Russia, as well as the operational situation on the road network in the transport emergency area, defined by the possibility of unlawful actions of attackers against vehicles, are not fully known.

The optimality of routes along which the material and technical equipment is delivered is defined in the article based on two partial criteria: security and secrecy, while maintaining restrictions on the value of transportation costs. Unlike the optimization by one criterion usually used when solving such problems, this allows to state the relevance of the approach proposed in this article within the problem of optimizing the organization of the material and technical support for equipment and personnel of the EMERCOM of Russia in the conditions of liquidating emergency situations on transport. The routes consist of road sections (hereinafter referred to as roads), each of which connects two points. Removing any of them from consideration leads to the removal of this road (section of road) from consideration according to the approach proposed below. The points are connected by a network of roads and include both transport objects (road junctions, bridges, tunnels, bottlenecks, etc.), the state of which determines the possibility of movement along the roads that make up the route, and points where equipment and personnel of the EMERCOM of Russia (consumers of material and technical means), as well as warehouses (bases) with stocks of material and technical means (suppliers) are located. The costs (transport costs) of transporting a unit of cargo along each road and its reliability indicator are known. The most reliable option for the delivery of material and technical means (supplies) needs to be chosen, which would require minimal costs (compared with all other options of the same reliability). The concept of solving the problem is as follows: all routes are ordered by reliability, and the most reliable are chosen, but only the ones that would allow the transportation of supplies in the required volumes. From the total number, the routes are chosen, the use of which will result in the minimum total costs of delivering the required volumes of supplies. 
In the course of solving the problem, the reliability indicators should be determined for routes and for the entire plan for the delivery of supplies to consumers, as well as the procedure for finding the optimal plan for the delivery of supplies, using the information system for officials of the management bodies of the EMERCOM of Russia, who are developing solutions to eliminating the consequences of emergency situations.

\section{MAIN PART}

The reliability of the road is naturally understood as the degree of confidence in the safety of its use in the course of material and technical support for equipment and personnel of the EMERCOM of Russia. The probability that the plan for the delivery of supplies to consumers during the liquidation of the consequences of emergency situations on transport does not undergo significant changes can be used as an indicator of the reliability of the road. However, due to the uniqueness of the conditions for eliminating the consequences of emergency situations on transport, the procedure for determining these probabilities is a complex task. Moreover, even if these probabilities are known, the task of determining the optimal option for using a network of roads in the area of eliminating the consequences of emergency situations on transport for the material and technical support for equipment and personnel of the EMERCOM of Russia is algorithmically quite complicated.

The theory of fuzzy sets will be used in the article to determine the reliability of roads, routes, and the entire plan for the delivery of material and technical means to consumers during the liquidation of the consequences of emergency situations on transport. The reliability of the road will be described with the truth value of the statement "the road is reliable", meaning that emergencies, including attackers (terrorists), are not able to significantly affect the transportation on this road. The reliability of the route is understood as the minimum of the reliabilities of the roads the route consists of. The reliability of the plan is understood as the minimum of the reliabilities of the routes used in this plan for the transportation of material and technical means to consumers. This method for calculating the reliability of the routes and the entire plan for delivering supplies to consumers during the liquidation of the consequences of emergency situations on transport is based on formula (1), because the statement "the route is reliable" is a conjunction of the statements "the road is reliable" for all roads making up this route. Similarly, the statement "the plan is reliable" is a conjunction of the statements "the route is reliable" for all the routes used to transport the supplies in this plan.

Let us consider several approaches to solving this problem.

The first approach is based on expert opinions. The linguistic variable "reliability" is considered in this approach with the expert participation (Zadeh, 1976; Leonenkov, 2005), along with the terms for roads making up the routes: "absolutely reliable", "very reliable", "reliable", etc. After this, the existing roads are classified in accordance with the above terms and sorted within each class according to the degree of truthfulness of the statements "this road is reliable".

In the second approach, a single generalized criterion is formed according to given partials. It must be noted that many methods have been developed when considering multicriteria optimization in order to reduce the set of partial criteria to a single generalized criterion (Podinovskij y Nogin, 1982; Anisimov et al. 2008), which allows to order the studied alternatives according to the values of this generalized criterion.

For the purposes set above, let us consider a problem with a fuzzy goal, as Zadeh and Bellman suggested at the time (Orlovskij, 1981; Zadeh y Bellman, 1970). The problem of ordering roads (alternatives) will be considered as a vector optimization problem with two partial criteria - for example, $f_{1}$ is the protection of 
the road and $f_{2}$ is the viewing depth. Thus, $f_{1}: U \rightarrow R^{1}, f_{2}: U \rightarrow R^{1}, U$ is the set of alternatives. Protection of the road is described by the number of posts arranged by security agencies per $100 \mathrm{~km}$ (pcs), the viewing depth is described by the average distance into the depth to which objects are viewed from the road $(\mathrm{m})$. It must be noted that both partial criteria can be maximized, i.e., the best alternatives correspond to large values of partial criteria. A partial fuzzy goal is formalized by a fuzzy set $X_{g}^{i}, i=1,2$ (for example, "almost $f_{i}^{*}$ ", where $f_{i}^{*}$ is the maximum value of the $i$-th partial criterion) with a membership function $\mu_{i}(x), x \in U, U$ is the universal set (the set of allowable alternatives), and $\mu_{i}(x)$ is the truth value of the fuzzy saying "the road $x$ is reliable."

Zadeh and Bellman consider linear functions as possible membership functions in the first approximation - the normalized deviation of the value of the partial criterion from the minimum, such as:

$$
\mu_{i}(x)=\frac{f_{i}(x)-f_{i}^{0}}{f_{i}^{*}-f_{i}^{0}}
$$

where $f_{i}^{0}$ is the minimum value of the criterion, and $f_{i}$ is the measure.

It is assumed that partial criteria are equally important. If not, the nonlinear relationships can be used to define membership functions - for example, the following relationship:

$$
\mu_{i}(x)=\left(\frac{f_{i}(x)-f_{i}^{0}}{f_{i}^{*}-f_{i}^{0}}\right)^{\alpha},
$$

or dependencies, sample charts of which are provided in Figure 1.
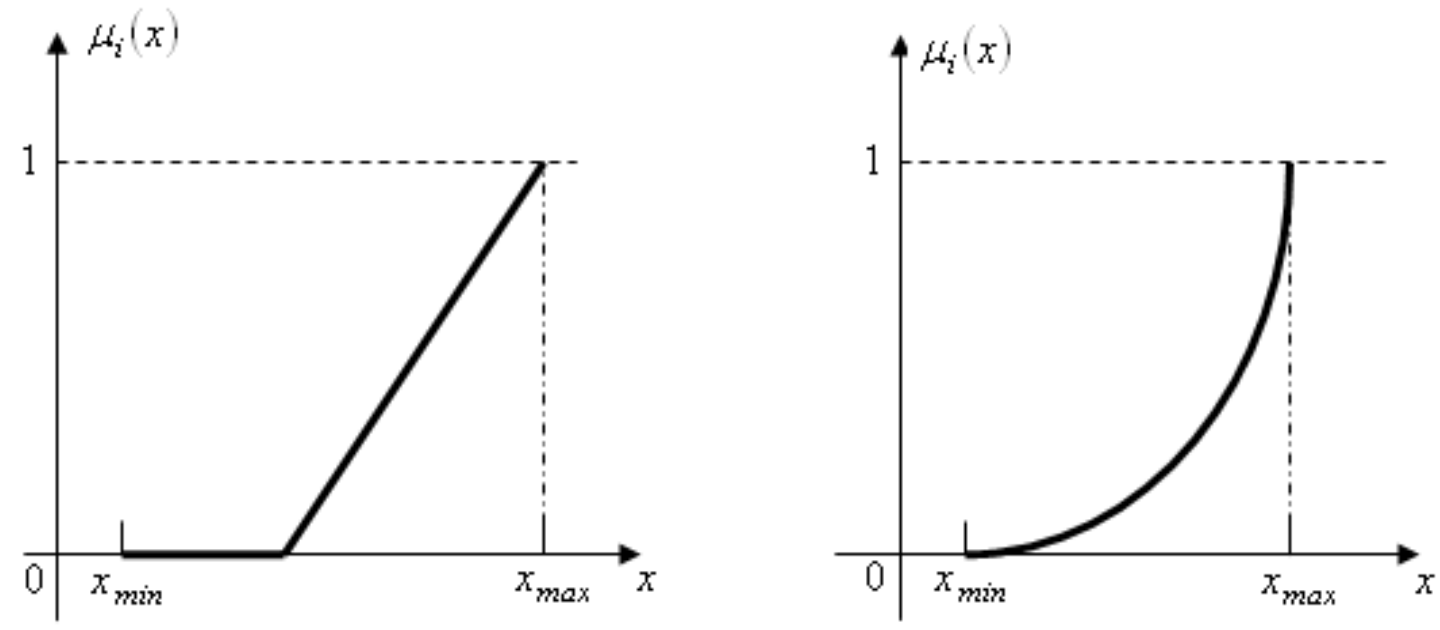

$\mathrm{x}_{\min }$ is the minimum point of the partial criterion, and $\mathrm{x}_{\max }$ is the maximum point of the partial criterion

Figure 1. Possible charts of membership function

A fuzzy goal is a conjunction of partial goals, and therefore the membership function $\mu(x)$ of the fuzzy set for the goal $X_{g}$ formalizing the fuzzy goal is the minimum membership function of fuzzy sets formalizing partial fuzzy goals: 


$$
\mu(x)=\min \left\{\mu_{1}(x), \mu_{2}(x)\right\}
$$

Let us provide an example to illustrate the proposed approach.

There are $f_{1}\left(x_{0}\right)=9$ posts on the road $x_{0}$ organized by the security agencies to prevent illegal actions of attackers (terrorists) against equipment and personnel (convoys) of the EMERCOM moving on the road, the viewing depth $f_{2}\left(x_{0}\right)$ is 150 meters. The function $f_{1}(x)$ takes values on the set of points $\{0,1,2,3,4,5,6,7,8,9,10,11,12,13,14,15\}$, the function $f_{2}(x)$ takes values on the set of points from the interval $[0 ; 400]$. These sets are universal sets for fuzzy sets formalizing fuzzy variable statements about the protection of the road and the viewing depth, respectively. It is required to determine the value of the generalized criterion "reliability of the road", assuming that

$$
\begin{gathered}
\mu_{1}(u)=\left\{\begin{array}{l}
0, \text { if } u=0,1,2,3 \\
\frac{u-3}{12}, \text { if } u=4,5,6,7,8,9,10,11,12,13,14,15^{\prime}
\end{array}\right. \\
\mu_{2}(v)=\frac{v}{400},
\end{gathered}
$$

where $u=f_{1}(x)$, and $v=f_{2}(x)$.

Charts of these functions are presented in Figures 2 and 3, respectively.

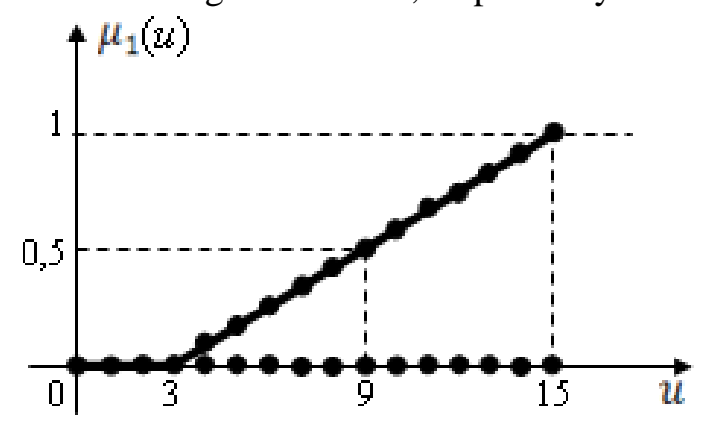

Figure 2. Chart of the function $\mu_{1}(\mathrm{u})$

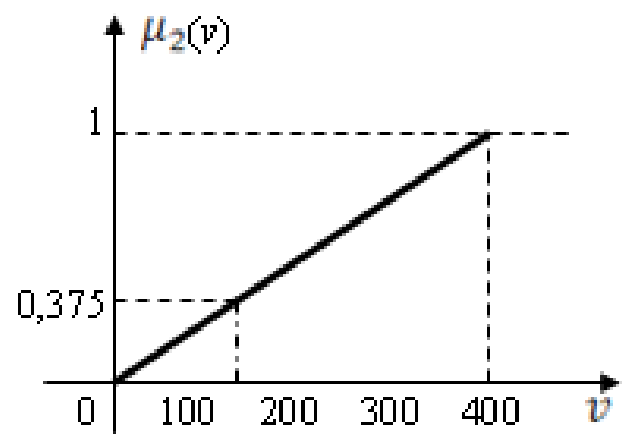

Figure 3. Chart of the function $\mu_{2}(v)$

Since $u=9$ for the road under consideration, then $\mu_{1}(9)=0,5$ (formula (6) or Figure 2), $v=150$, and $\mu_{2}$ $(150)=0,375$ (formula (7) and Figure 3). It has been obtained that the degree of the confidence that the 
road is secure (the truth of the statement "the road is secured") in this case is 0.5 ; the degree of confidence for the viewing depth is 0.375 . As such, according to formula (5), it has been obtained that the reliability indicator for the road under consideration is equal to the minimum of these two numbers, i.e., equal to 0.375 .

The authors propose another approach to building a single generalized criterion according to the given partial criteria.

It must be noted that this approach is based on the fuzzy inference method of Mamdani and Assilian (1975), and it is proposed to order the roads by the value of the function $\mu$ (x) - the larger this value is, the more reliable the road is.

This approach is considered based on the example related to the assessment of the road reliability.

As part of the below presentation of the proposed approach, it must be noted that the road reliability (output variable) is a fuzzy linguistic variable "reliability of the road" with such terms as "very reliable", "substantially reliable", and "dangerous" (Figure 4). These terms are formalized using fuzzy sets on the universal set of number estimates [0;5].

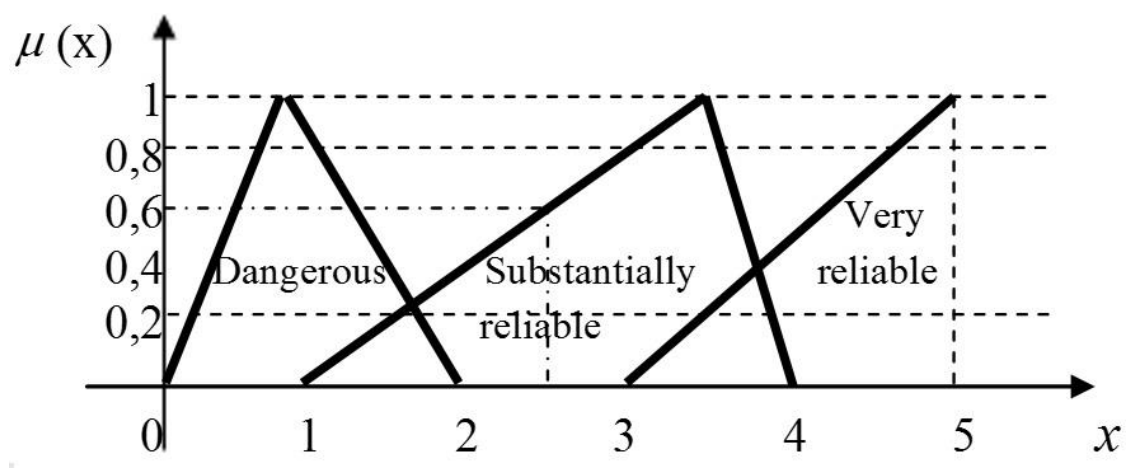

Figure 4. Chart of membership functions for the terms of the linguistic variable "reliability of the road"

The level of reliability depends on two input fuzzy linguistic variables, such as "protection of the road" with terms "fully protected" and "not very protected", and "viewing depth" with such terms as "very secretive", "almost open", and "open".

The set of possible values of the number of posts arranged by security agencies per 100 kilometers of the road will be used as a universal set for the first of those variables.

This set is denoted as $U$, let $U=[0 ; 10]$, the universal set for the second variable is the set of mean depths on which objects are viewed from the road. This set is denoted as $V, V=[0 ; 400]$.

The membership functions $\mu(\mathrm{u})$ of the terms of these linguistic variables are presented in Figures 5 and 6 . 


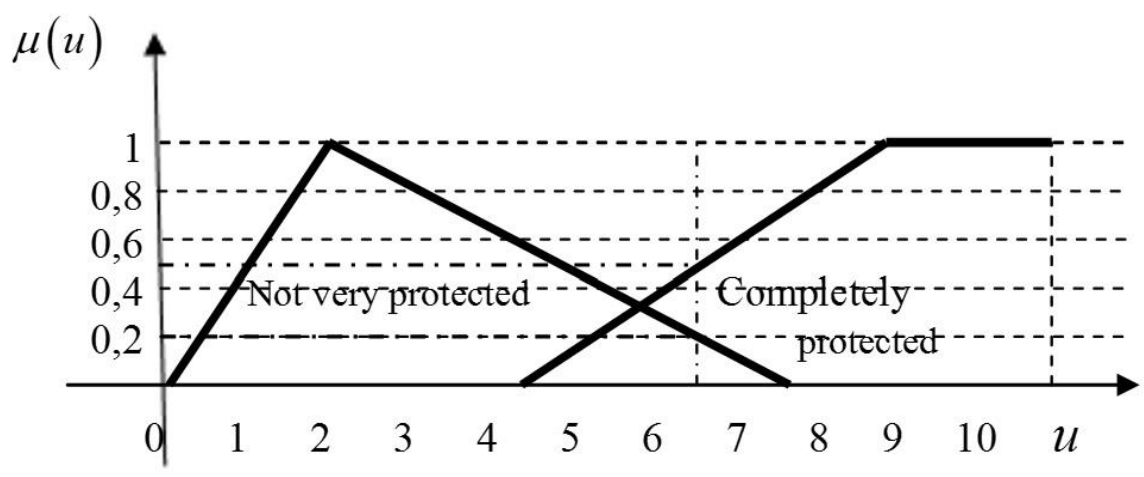

Figure 5. The terms of the variable "protection of the road" $u$ is the number of posts per $100 \mathrm{~km}$, pcs

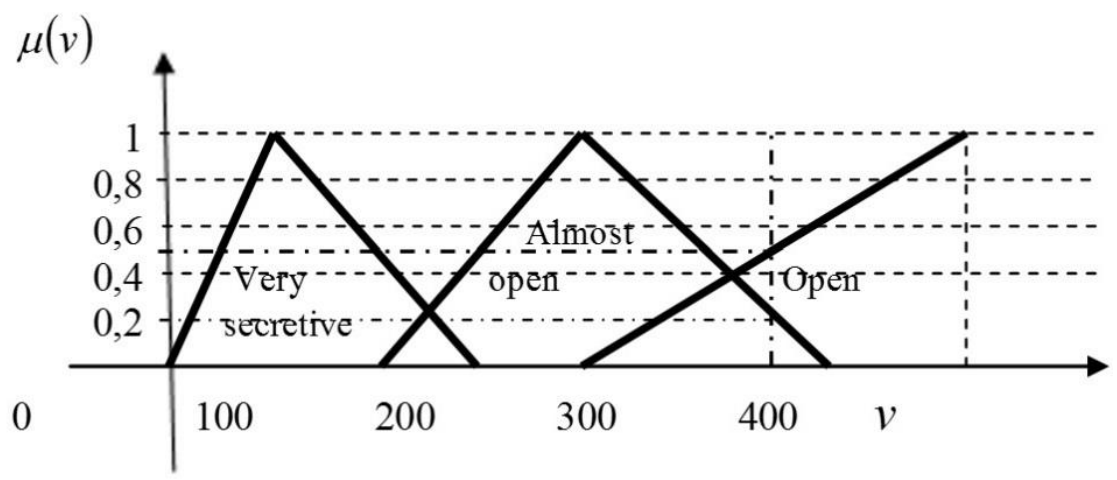

Figure 6. Terms of the variable "viewing depth" $v$ is the viewing range, $\mathrm{m}$

The knowledge base containing the information about the term of the output variable depending on the combination of values (terms) of the input variables is presented in Table 1.

Table 1. Knowledge base

\begin{tabular}{cccc}
\hline $\begin{array}{c}\text { "Protection of the } \\
\text { road" }\end{array}$ & "Open" & $\begin{array}{c}\text { "Viewing depth" } \\
\text { "Almost open" }\end{array}$ & $\begin{array}{c}\text { "Very secretive" } \\
\text { "Very reliable" }\end{array}$ \\
"Completely protected" & $\begin{array}{c}\text { "Very reliable" } \\
\text { "Substantially reliable" } \\
\text { reliable" }\end{array}$ & "Substantially reliable" & "Dangerous" \\
"Not very protected" & & & \\
\hline
\end{tabular}

For the road under evaluation, the numerical values of the input variables are set - for example, six posts arranged by security agencies per $100 \mathrm{~km}$ for the variable "protection of the road", and 300 meters for the variable "viewing depth". Using these input data and the charts of membership functions, the level of the confidence can be found (the values of the corresponding membership functions) that a certain term is the value of the linguistic variable (Table 2).

Table 2. Reliability of terms of the output variable for the given $u=6$ and $v=300$

\begin{tabular}{|c|c|c|c|}
\hline \multirow{2}{*}{ "Protection of the road" } & \multicolumn{3}{|c|}{ "Viewing depth" } \\
\cline { 2 - 4 } & "Open" (0.5) & "Almost open" (0.25) & "Very secretive" (0) \\
\hline "Completely protected" (0.5) & "Very reliable" (0.5) & "Very reliable" (0.25) & "Substantially reliable" (0) \\
\hline "Not very protected" (0.2) & "Substantially & "Substantially reliable" & "Dangerous" (0) \\
& reliable" (0.2) & $(0.2)$ & (0) \\
\hline
\end{tabular}


According to Figure 5 and Figure 6 (or formulas (6)-(7)), the confidence that the variable "protection of the road" has values "completely protected" is 0.5 , "not very protected" -0.2 ; the confidence that the terms of the variable "viewing depth" have values "very secretive" is 0 , "almost open" -0.25 , and "open" -0.5 .

For all possible combinations of the values of these variables from the knowledge base, the value of the evaluation of the output variable "road reliability" is determined (the corresponding term), as well as the value of the membership function (our confidence that the value of the variable "road reliability" is this term).

For example, if the confidence that the value of the variable "protection of the road" is the term "completely protected" equals to 0.5 , and the confidence that the value of the variable "viewing depth" is the term "open" equals to 0.5 , then the term "very reliable" will be used as the value of the output variable with confidence equal to the minimum of these two numbers (formula (1)).

Further, based on the results obtained and using the information on membership functions, the level of confidence can be found (the value corresponding to the membership function) that the terms of the output variable "road reliability" deserve specific numerical estimates. Then, using the center of gravity method, for example, the final result is obtained - the score by the five-point system of the road under consideration.

Positive values of membership functions exist only for two terms of the output variable: "very reliable" and "substantially reliable". With the considered values of the input variables, the term "very reliable" can turn out to be the value of the output variable only in two cases, only in the situation of combining (conjunction) two combinations of values of the input variables:

1) the value of the variable "protection of the road" is the term "completely protected", the value of the variable "viewing depth" is the term "open", the value of the membership function for this combination is 0.5 (formula (5)); and

2) the value of the variable "protection of the road" is the term "completely protected", and the value of the variable "viewing depth" is the term "almost open", the value of the membership function for this combination is 0.25 (formula (5)).

Using formula (2), it can be found that for the considered values of the input variables, the degree of confidence that the term "very reliable" is the value of the output variable equals to the maximum of the numbers 0.5 and 0.25 , i.e. this confidence level is 0.5 .

Similarly, the degree of confidence that the term "substantially reliable" is the value of the output variable for given input values equals to 0.2 .

Let us determine the degree of membership for various numerical values of the output variable (in increments of 0.5 ) for the indicated combinations of terms of input variables (Table 3) and for $u=6, v=$ 300.

Table 3. Degrees of membership for various values of the output variable for $u=6$ and $v=300$

\begin{tabular}{ccccccccccccc}
\hline Terms of the output & \multicolumn{11}{c}{ Values of the output variable $(\boldsymbol{x})$} \\
variable & $\mathbf{0 . 0}$ & $\mathbf{0 . 5}$ & $\mathbf{1 . 0}$ & $\mathbf{1 . 5}$ & $\mathbf{2 . 0}$ & $\mathbf{2 . 5}$ & $\mathbf{3 . 0}$ & $\mathbf{3 . 5}$ & $\mathbf{4 . 0}$ & $\mathbf{4 . 5}$ & $\mathbf{5 . 0}$ \\
"Very reliable" $(0.5)$ & 0 & 0 & 0 & 0 & 0 & 0 & 0 & 0.25 & 0.5 & 0.75 & 1 \\
"Substantially reliable" (0.2) & 0 & 0 & 0 & 0.2 & 0.4 & 0.6 & 0.8 & 1.0 & 0 & 0 & 0 \\
\hline
\end{tabular}


For example, the degree of membership of a numerical value 2 to the term "very reliable" is zero (Figure 4 ); similarly, the degree of membership of the value 2.5 to the term "substantially reliable" is 0.6 .

The degrees of membership of various numerical values of the output variable are provided in Table 4, with due consideration for the degree of membership of the corresponding choice of the output term. It must be noted that these reliabilities are equal for $=6, v=300: 0.5$ for the term "very reliable" and 0.2 for the term "substantially reliable".

Table 4. Degrees of membership for various values of the output variable for $u=6$ and $v=300$

\begin{tabular}{|c|c|c|c|c|c|c|c|c|c|c|c|}
\hline $\begin{array}{c}\text { Terms of the output } \\
\text { variable }\end{array}$ & \multicolumn{10}{|c|}{ Values of the output variable $(\boldsymbol{x})$} \\
\cline { 2 - 26 } & $\mathbf{0 . 0}$ & $\mathbf{0 . 5}$ & $\mathbf{1 . 0}$ & $\mathbf{1 . 5}$ & $\mathbf{2 . 0}$ & $\mathbf{2 . 5}$ & $\mathbf{3 . 0}$ & $\mathbf{3 . 5}$ & $\mathbf{4 . 0}$ & $\mathbf{4 . 5}$ & $\mathbf{5 . 0}$ \\
\hline "Very reliable" $(0.5)$ & 0 & 0 & 0 & 0 & 0 & 0 & 0 & 0.25 & 0.5 & 0.5 & 0.5 \\
\hline "Substantially reliable" $(0.2)$ & 0 & 0 & 0 & 0.2 & 0.2 & 0.2 & 0.2 & 0.2 & 0 & 0 & 0 \\
\hline$\mu_{E}(x)$ & 0 & 0 & 0 & 0.2 & 0.2 & 0.2 & 0.2 & 0.25 & 0.5 & 0.5 & 0.5 \\
\hline
\end{tabular}

The values of the membership function $\mu_{E}(x)$ of the fuzzy set "value of the output variable" for a set of values of input variables $u=6, v=300$ are provided in the last row of Table 4, i.e., the degree of confidence that a road with such values of input variables deserves an appropriate assessment. The values in the last row are calculated based on formula (2).

There are several approaches for obtaining a final assessment of the road reliability (Orlovskij, 1981). The "center of gravity" is used as an estimate, i.e., the ratio of the sum of the products of the elements from the first row of Table 4 to the corresponding elements from its last row to the sum of the elements from its last row:

$$
\frac{1,5 \cdot 0,2+2 \cdot 0,2+2,5 \cdot 0,2+3 \cdot 0,2+3,5 \cdot 0,25+4 \cdot 0,5+4,5 \cdot 0,5+5 \cdot 0,5}{0,2+0,2+0,2+0,2+0,25+0,5+0,5+0,5}=\frac{9,425}{2,55}=3,696
$$

Based on the result, it can be concluded that the assessment equal to four seems to be quite reasonable.

\section{CONCEPT OF DETERMINING THE SOLUTION OF THE TRANSPORT PROBLEM}

At this stage of solving the problem considered in the article, the issues of using the "most reliable" communications obtained above must be considered as part of the transport problem. Since the approach used for this purpose is considered in detail in (Chernykh y Kopkin y Skoptsov, 2015; Chernykh y Kozlova, y Vilkov, 2015), it is presented in this article at a conceptual level, referring the reader to that article, which provides a detailed description of this approach.

The most cost-effective route is found for each "warehouse-consumer" pair assuming that any road can be used and using the algorithm for finding the shortest route (Vagner, 1972; Khu, 1974). The transport problem is solved using the obtained routes (Vagner, 1972). The reliability of the resulting plan is found. The choice of the optimal route for cars with limited bandwidth in the regional road network, including the road network in settlements under the conditions of eliminating the consequences of emergency situations on transport, is discussed in detail in (Malygin y Krylatov y Shirokolobova, 1974; Krylatov et al. 2017; Krylatov y Zakharov y Malygin, 2016).

It is prohibited to use the roads with reliability equal to or less than the reliability of the resulting plan. The most cost-effective route is again found for each "warehouse-consumer" pair using the algorithm for finding the shortest route (using only roads that are not prohibited). The transport problem is solved using the obtained routes. The reliability of the resulting plan is found. 
It is prohibited to use the roads with reliability equal to or less than the reliability of the resulting plan. This iterative process continues until the problem is obtained where prohibited routes are used in the solution, which means that the task cannot be solved without using them.

\section{DISCUSSION}

The transport problem considered at the penultimate stage has allowable plans, in each of which only routes that are not prohibited can be used, and the reliability of any of these plans is the highest. The optimal plan for this problem is also notable for the fact that the total cost of its implementation is the lowest in comparison with all other allowable plans for the same problem.

\section{CONCLUSION}

The authors believe that the problem under consideration is of interest not only for the EMERCOM of Russia, but also for security and commercial agencies. This is due to the fact that difficulties with the delivery of cargo can arise not only due to natural disasters or the actions of attackers (terrorists). For example, they can also arise as the consequences of traffic accidents. It is clear that appropriate adjustments in the definition of input and output variables should be made using the proposed approach in solving problems with other causes of traffic failures, and this requires additional study, which may be the subject of further research.

\section{REFERENCES}

Anisimov, V. G., Anisimov, E. G., Bystrov, A. G., Lobas, E. V. (2008). Metod otsenivaniya obosnovannosti upravlencheskikh reshenij [Method for assessing the validity of management decisions]. Vestnik Rossijskoj tamozhennoj akademii, 2, 103-106.

Anisimov, V. G., Anisimov, E. G., Botvin, G. A. (2006). Investitsionnyj analiz v usloviyakh neopredelennosti [Investment analysis in the face of uncertainty]. St. Petersburg: Izd-vo SPbGPU.

Averkin, A. N., Batyrshin, I. Z., Blishun, A. F., Silov, V. B., Tarasov, V. B. (1986). Nechetkie mnozhestva $\mathrm{v}$ modelyakh upravleniya $\mathrm{i}$ iskusstvennogo intellekta [Fuzzy Sets in Management and Artificial Intelligence Models]. Moscow: Nauka.

Borisov, A. N., Krumberg, O. A., Fedorov, I. P. (1990). Prinyatie reshenij na osnove nechetkikh modelej: Primery ispol'zovaniya [Decision based on fuzzy models: Initial use]. Riga: Zinatne.

Chernykh, A. K., Kozlova, I. V., Vilkov, V. B. (2015). Issues of forecasting of material supply using indirect mathematical models. Problems of risk management in the technosphere, 4(36), 107-117.

Chernykh, A.K., Kopkin, E.V., Skoptsov, A.A. (2015). Forecasting of management of transportations in the conditions of the emergency situation of regional scale on transport, Problems of technosphere risk management, 2, 56-65.

Khu, T. (1974). Tselochislennoe programmirovanie i potoki v setyakh [Integer programming and network threads]. Moscow: Mir.

Kosko, B. (1994). Fuzzy systems as universal approximators. IEEE Transactions on Computers, 43(11), 1329-1333. DOI: $10.1109 / 12.324566$ 
Krylatov, A., Shirokolobova, A., Zakharov, V., Malygin, I. (2017). Non-smooth resource allocation problem, 2017 Constructive Nonsmooth Analysis and Related Topics (dedicated to the memory of V.F. Demyanov) (CNSA), St. Petersburg, Russia, May 22-27, 2017. DOI: 10.1109/CNSA.2017.7973977

Krylatov, A., Zakharov, V., Malygin, I. (2016). Competitive traffic assignment in road networks, Transport and Telecommunication, 17(3), 212-222.

Leonenkov, A. V. (2005). Nechetkoe modelirovanie v srede MATLAB i fuzzy TECH [Fuzzy modeling in MATLAB and fuzzy TECH]. St. Petersburg: BKHV-Peterburg.

Malygin, I. G., Krylatov, A. Yu., Shirokolobova, A. P. (1974). Fire engines routing problem in congested urban traffic area, Problems of technosphere risk management, 3(43), 87-95.

Mamdani, E. H., Assilian, S. (1975). An experiment in linguistic synthesis with fuzzy logic controller, International Journal of Man-Machine Studies, 7(1), 1-7. DOI: 10.1016/S0020-7373(75)80002-2

Orlovskij, S. A. (1981) Problemy prinyatiya reshenij pri nechetkoj iskhodnoj informatsii [Decisionmaking problems with fuzzy initial information]. Moscow: Nauka.

Podinovskij, V. V., Nogin, V. D. (1982). Poreto-optimal'nye resheniya mnogokriterial'nykh zadach [Poreto-optimal solutions for multicriteria problems]. Moscow: Nauka.

Shtovba, S. D. (2001). Vvedenie v teoriyu nechetkikh mnozhestv i nechetkuyu logiku [Introduction to fuzzy set theory and fuzzy logic]. Vinnitsa: UNIVERSUM-Vinnitsa.

Shtovba, S. D. (2007). Proektirovanie nechetkikh sistem sredstvami MATLAB [Designing Fuzzy Systems Using MATLAB]. Moscow: Goryachaya liniya - Telekom.

Vagner, G. (1972). Osnovy issledovaniya operatsij [Operations Research Fundamentals]. Vol. 1. Moscow: Mir.

Vilkov, V. B., Kozlova, I. V. (2015). Forecast of the optimal options of delivery of material supply under conditions of regional emergency on the basis of the fuzzy set theory. Natural and technological risks (physics-mathematical and applied aspects), 3, 10-17.

Yakhyaeva, G. E. (2006). Nechetkie mnozhestva i nejronnye seti [Fuzzy sets and neural networks]. Moscow: Binom.

Zadeh, L. (1965). Fuzzy sets. Information and Control, 8(3), 338-353. DOI: 10.1016/S00199958(65)90241-X

Zadeh, L. (1976). The concept of a linguistic variable and its application to making approximate decisions. Moscow: Mir.

Zadeh, L. A., Bellman, R. E. (1970). Decision-making in a fuzzy environment, Management Science, 17, 141-164. DOI: 10.1287/mnsc.17.4.B141 